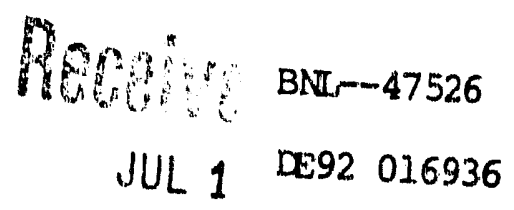

\title{
FRACTAL POLYZIRCONOSILOXANE CLUSTER COATINGS
}

\author{
Dr. T. Sugama \\ Energy Efficiency and Conservation Division. \\ Department of Applied Science \\ Brookhaven National. Laboratory \\ Upton, NY 11973
}

\begin{abstract}
Fractal polyzirconosiloxane (PZS) cluster films were prepared through the hydrolysis-polycondensation-pyrolysis synthesis of two-step $\mathrm{HCl}$ acid- $\mathrm{NaOH}$ base catalyzed sol precursors consisting of $\mathrm{N}$ - [3-(triethoxysilyl)propy 1]-4,5-dihydroimidazole, $\mathrm{Zr}\left(\mathrm{OC}_{3} \mathrm{H}_{7}\right)_{4}$, methanol, and water. When amorphous PZSs were applied to aluminum as protective coatings against $\mathrm{NaCl}$-induced corrosion, the effective film was that derived from the sol having a $\mathrm{pH}$ near the isoelectric point in the positive zeta potential. region. The following four factors played an important role in assembling the protective PZS coating films: 1) a proper rate of condensation, 2) a moderate ratio of $\mathrm{Si-O-Si}$ to Si-O-Zr linkages formed in the PZS network, 3) hydrophobic characteristics, and 4) a specific microstructural geometry, in which large fractal clusters were linked together.
\end{abstract}

\section{INTRODUCTION}

We have described the characteristics of an inorganic polymetallosiloxane (PMS) film, formed by the pyrolysis of sol precursor-induced organopolymetallosiloxane xerogels, intencied for use as corrosion-protective coatings on aluminum substrates 1.2 . The chemical components of the precursor solution consisted of monomeric organosilanes, metal alkoxides $\left[\mathrm{M}_{(\mathrm{OC}} \mathrm{H}_{7}\right)_{4}$, M: $\mathrm{Zr}, \mathrm{Ti}$, and $\mathrm{Ge}$, methanol, water, and hydrochloric acid. Our findings suggested that the following chemical factors play an important role in ensuring that the PMS coatings afford adequate protection : 1) the addition of $\mathrm{HCl}$ used as a hydrolysis accelerator for the organosilanes, and $\mathrm{M}\left(\mathrm{OC}_{3} \mathrm{H}_{7}\right)_{4}$, which produces

This work was performed under the auspices of the U.S. Department. of Energy, Washington, DC, under contract No. DF-ACO2-7GCHOOOIG., p 
a clear sol solution, thereby aiding in the formation of smooth, uniform coating layers, 2) the organosilane to $\mathrm{M}\left(\mathrm{OC}_{3} \mathrm{H}_{7}\right)_{4}$ ratios are critical in achieving spreadability of the sol solution on Al surfaces, and in leaving a minimum amount of organic and crystalline by-products in the organopolymetallosiloxane xerogel. formed at a sintering temperature of $\approx 150^{\circ} \mathrm{C}, 3$ ) moderate densffications of the Si-O-M linkages in amorphous PMS networks derived from the $300^{\circ} \mathrm{C}$-pyrolytic conversion of xerogel are needed to minimize the development of stress cracks in the films, and 4) the formation of covalent oxane bonds at the interfaces between the PMS and aluminum substrate increase the likelihood of strong adhesion forces.

However, all the present information on the PMS coatings were obtained from experiments with the sol precursor solution in the presence of acid catalysts. The objective of the present study was to investigate the characteristics of polyzirconosiloxane (PZS) coating films derived from two-step, acid-base-catalyzed precursors consisting of $\mathrm{N}-[3$ (triethoxysilyl)propyl)-4,5-dihydroimidazole (TSPI), $\operatorname{Zr}\left(\mathrm{OC}_{3} \mathrm{H}_{7}\right)_{4}$, methanol, and water, over a broad $\mathrm{pH}$ range of 1.0 to 13.0 .

\section{MATERIALS}

N-[3-(triethoxysilyl)propyl]-4,5, -dihydroinidazole (TSPI), supplied by Petrarch Systems Ltd., and zirconium (IV)isopropoxides $\left[\mathrm{Zr}\left(\mathrm{OC}_{3} \mathrm{H}_{7}\right)_{4}\right]$ obtained from Alfa Products, were used as the network-forming monomeric material. The film-forming mother-liquor, which served as the precursor solution, was prepared by incorporating the TSPI- $2 \mathrm{r}\left(\mathrm{OC}_{3} \mathrm{H}_{7}\right)_{4}$ mixture into a methyl alcohol/water mixture containing $\mathrm{HCl}$ as a hydrolysis accelerator. HCl-catalyzed hydrolysis of the alkoxy groups in the TSPI and $\mathrm{Zr}\left(\mathrm{OC}_{3} \mathrm{H}_{7}\right)_{4}$ provided a clear colloidal precursor solution. To increase the $\mathrm{pH}$ of the acid solution, $\mathrm{NaOH}$ as a condensation promoter was added to the mother-liquors. Table 1 shows the compositions of the precursor solutions prepared through such a two-step acid-base"catalyzed method, as a function of ph.

Table 1

Compoutiten of Sol Precursor solutione in The pH Range of 1.1 to 12.8

\begin{tabular}{|c|c|c|c|c|c|c|}
\hline \multirow[b]{3}{*}{26} & \multirow[b]{2}{*}{ TSPI } & \multirow[b]{2}{*}{$2 \mathrm{r}\left(\mathrm{OC}, \mathrm{H}_{4}\right)}$. & \multirow[b]{2}{*}{$\mathrm{CH}, \mathrm{OH}$} & \multirow[b]{2}{*}{ Watar } & $\mathrm{HCl}$ & $\mathrm{N} \mathrm{OH}$ \\
\hline & & & & & we / TSPI * & WeO / ISPI + \\
\hline & \&Cl & wha & wh & ust & $25\left(0 c_{2} y_{1}\right)$ & $25\left(0 C_{2}+t_{2}\right)$ \\
\hline 1.1 & 7.7 & 5.1 & 7.7 & 79.5 & 50.0 & 0.0 \\
\hline 2.6 & 7.7 & 3.1 & 7.7 & 79.5 & so. 0 & 10.4 \\
\hline 7.1 & 7.7 & 3.1 & 7.7 & 79.5 & 50.0 & 14.0 \\
\hline 8.6 & 7.7 & 5.1 & 7.7 & 79.5 & 50.0 & 18.0 \\
\hline 12.5 & 7.7 & s. 1 & 3.7 & 79.5 & 50.0 & 26.0 \\
\hline 12.8 & $\therefore .7$ & 5.1 & $\therefore .7$ & 79.5 & 50.0 & 39.0 \\
\hline
\end{tabular}


The metal surstrate was 606i-T6 aluminum sheet, containing the following chemical constituents: 96.3 wto Al, 0.6 wto S1, 0.7 wes $\mathrm{Fe}, 0.3$ wts $\mathrm{Cu}, 0.2$ wto $\mathrm{Mn}, 1.0$ wts $\mathrm{Mg}, 0.2$ wtz $\mathrm{Cr}, 0.3$ wto $\mathrm{Zn}, 0.2$ wts $\mathrm{Ti}$, and $0.2 \mathrm{wt}$ other.

The aluminum surfaces were coated by PZS xerogels in the following sequence. The aluminum surfaces were wiped with acetone-soaked tissues to remove any gross surface contaminants. The aluminum substrates were then dipped into the colloidal precursor solution at ambient temperature. After dipping, the substrates were withdrawn slowly from the soaking bath. The precursor wetted substrate surfaces were preheated in an oven for $30 \mathrm{~min}$ at $100^{\circ} \mathrm{C}$ to yield a xerogel coating film. The xerogel films were subsequently pyrolyzed for $15 \mathrm{~min}$ in air at temperatures of $250^{\circ} \cdot 300^{\circ} \mathrm{C}$.

\section{RESULTS AND DISCUSSION}

\section{SOL. PRECURSOR SOLUTIONS}

Because a sol is a colloidal suspension of solid particles in a liquid, the zeta potential $(z-p)$, is an important guide to understanding the growth rate of colloidal and polymeric solid particles. Figure 1 shows the variation of $z-p$ value as a function of the $\mathrm{pH}$ of the precursor solution. The particle size of these clusters in an aqueous solution may range from $\approx 1$ to $\approx$ $20 \mathrm{~nm}^{3}$.

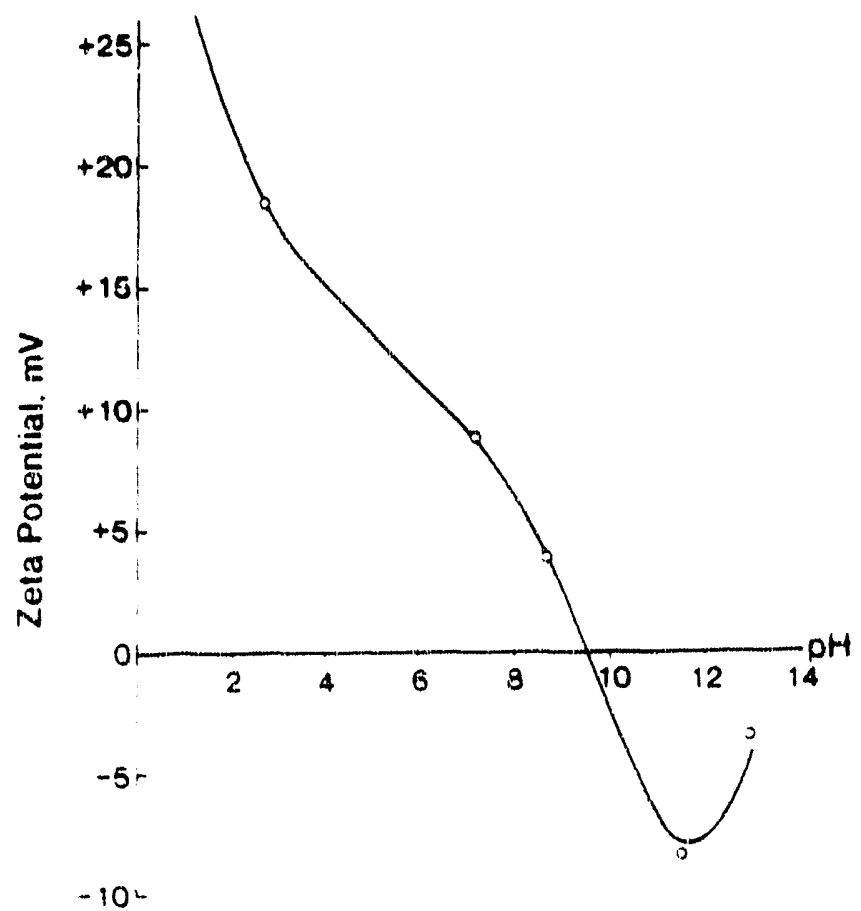

Figure 1. Changes in zeta potential as a function of the pit of the sol precursors. 
At $\mathrm{pH}$ 1.1, the protons, $\mathrm{H}^{+}$, in the solution favorably attack the regative hydroxyl groups on the cluster particles; consequently, the overall net effective charge on the polydispersities measures $+26.7 \mathrm{mV}$. When $\mathrm{NaOH}$ was incorporated into this acid precursor solution, the presence of $\mathrm{OH}^{-}$led to a charge reversal. As shown in the resultant curve, the. $z$-p value decreases progressively with the increased $\mathrm{pH}$ of the solutions. The isoelectric point (IEP), where there is no net charge (zero $\mathrm{mV}$ of $z-p$ ) on the particle surfaces, occurs around $\mathrm{pH} 9.5$. With further increase in $\mathrm{pH}$, the $z-\mathrm{p}$ charge becomes negative; beyond a $\mathrm{pH}$ of 11.5, the surface charge shifts to near zero potential in the negative regions.

To better understand these data, the microstructure of xerogel films deposited on the aluminum (Al) substrate was observed with SEM. The films were prepared in a vacuum oven at $70^{\circ} \mathrm{C}$. The surface images of films from sols with $\mathrm{pH} 1.1,2.6$, 8.6, and 11.5, are shown in Figures 2 and 3. The SEM micrograph (fig. 2-a) of the $\mathrm{pH} 1.1$ sol-derived xerogel display the continuous features of a smooth transparent film. As seen in Fi.gure 2-(b), an increase in the $\mathrm{pH}$ from 1.1 to 2.6 resulted in a change in the morphology of film, which then showed two different cluster species, a randomly distributed branch-type polymer, and a transparent-type polymer. With a sol of $\mathrm{pH} 8.6$, which is near the IEP, the microtexture of film (fig. 3-c) disclosed a compacted version of highly branched clusters, which completely covered the Al substrates. There were no transparenttype clusters present. Thus, use of the combination of acid and base catalysts promotes decoupling between hydrolysis and condensation. At $\mathrm{pH}$ 11.5, the SEM image (fig. 3-d) showed that the film had a large number of microcracks. The reason for the development of microcracks may be due to the chemical reaction between high $\mathrm{pH}$ precursor and $\mathrm{Al}$ substrate; namely, the $\mathrm{OH}^{-}$ions in the precursor favorably react with $A 1$ ion in the $A 1$ oxides lattice to promote the pitting-type corrosion of Al alloys ${ }^{4} 5$. Such an interfacial reaction may lead to bond breakage and reformation of the primary building polymer conformation.

Before surveying the properties of the pyrolyzed PZS films deposited on the AI substrates, we investigated the thermal behavior of $\mathrm{Zr}$-incorporated organosilanes derived from sols with different pHs, using TGA-DTA. Figure 4 illustrates the TGA and DTA curves which reveal the decomposition characteristics during pyrolysis of samples of $150^{\circ} \mathrm{C}$-preheated xerogel powders. The TGA curve for the sol-derived xerogel samples at pH 1.l. indicates that there are three decomposition states; the first begins at the onset temperature $\left(T_{d 1}\right)$ near $250^{\circ} \mathrm{C}$, the second occurs between $\approx 380^{\circ}$ and $\approx 470^{\circ} \mathrm{C}$, and the third from $\approx 500^{\circ}$ to $\approx 610^{\circ} \mathrm{C}$. 


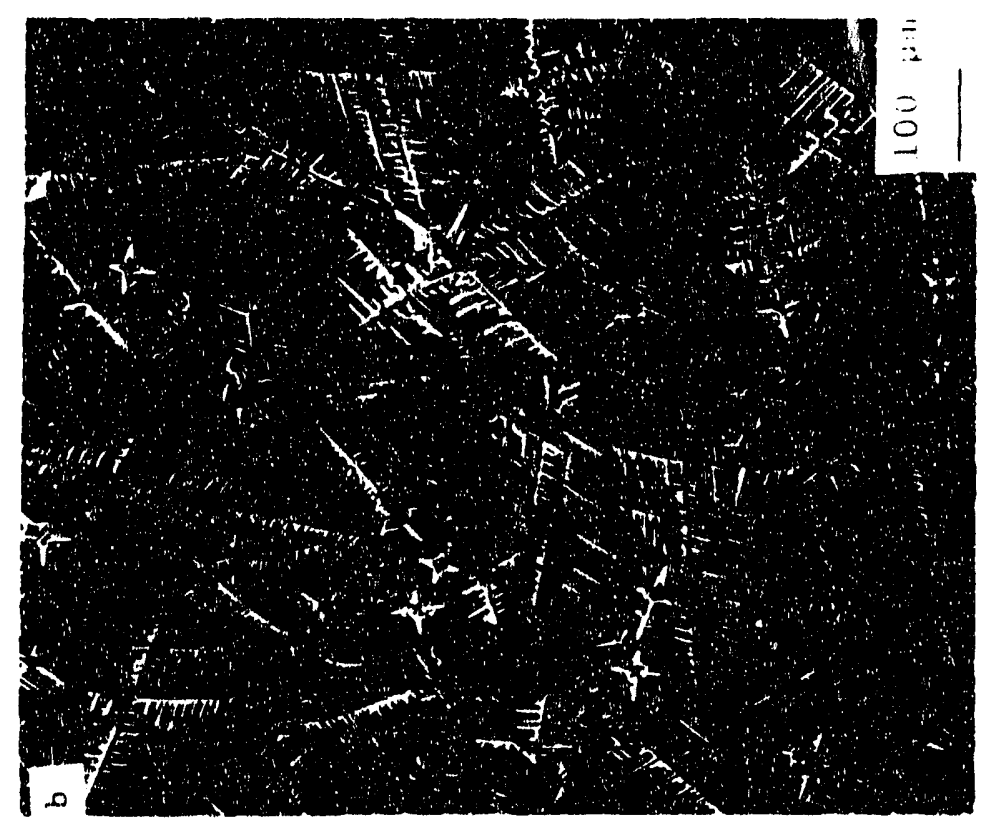

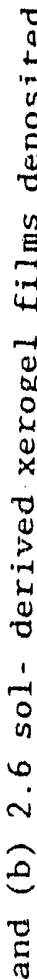

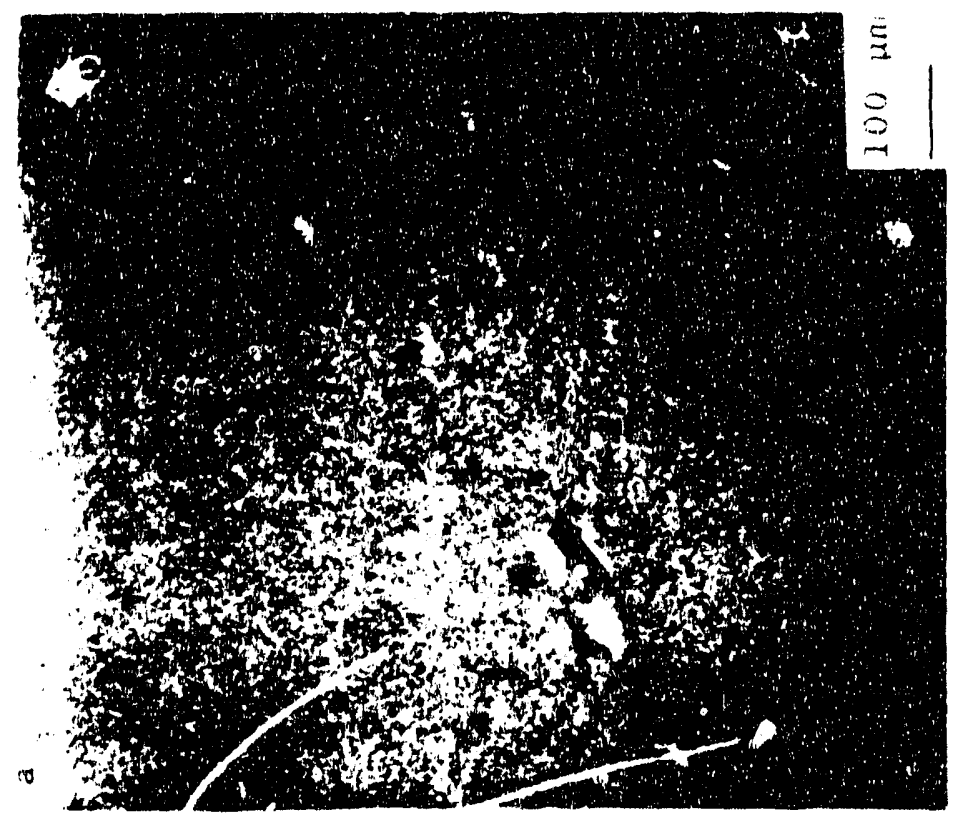

i. 


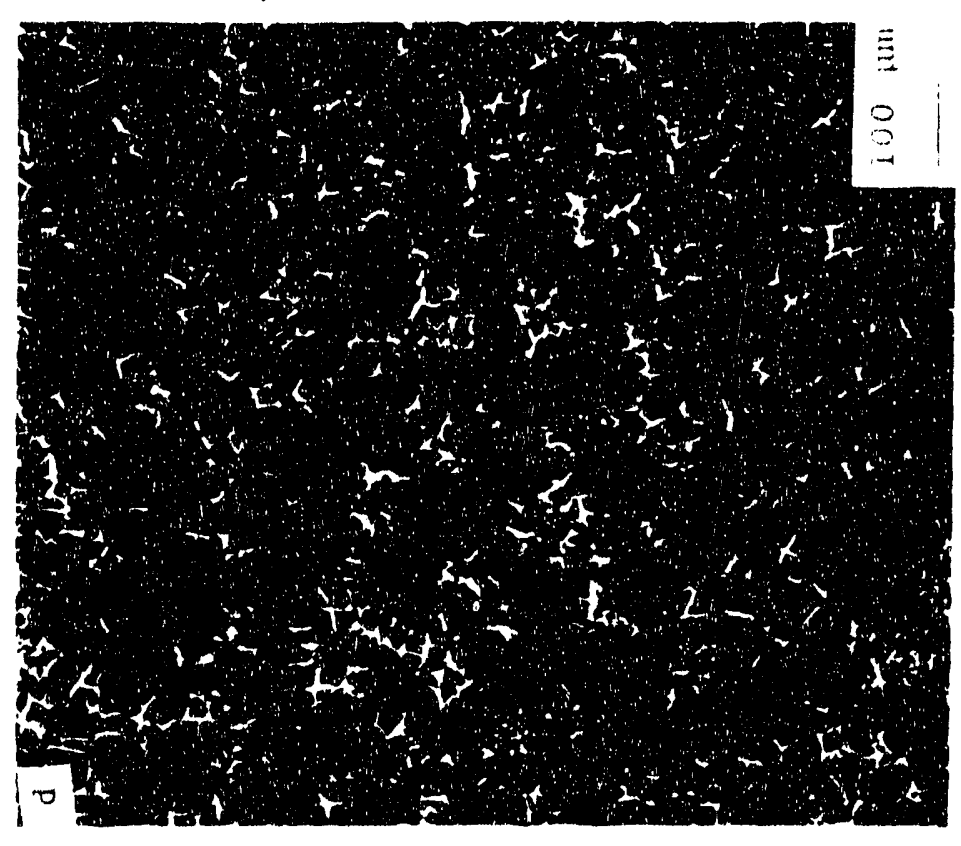

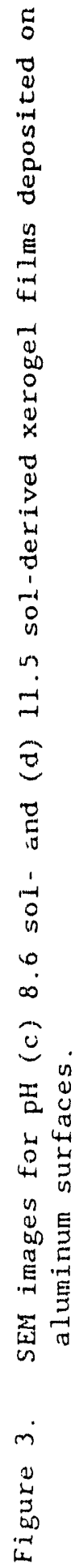

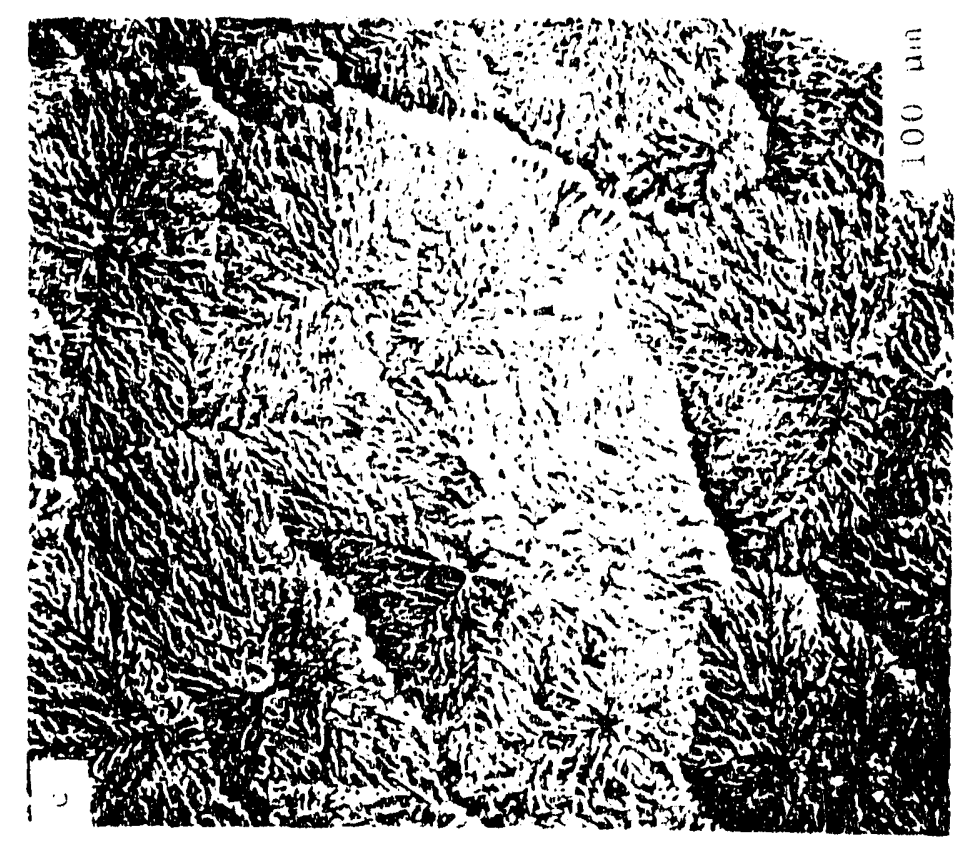


Compared to the TGA curve of the $\mathrm{pH} 1.1$ samples, the shape of the curve changes in the $\mathrm{NaOH}$-incorporated samples. There are three notable differences: 1) an increase in the $\mathrm{pH}$ of the sol. lowers the temperature of onset of thermal decomposition in the third stage, 2) the intensity of the DTA peak at $420^{\circ} \mathrm{C}$, corresponding to the second decomposition, significantly decreases, and 3 ) the total weight loss of samples at $610^{\circ} \mathrm{C}$ decreases with increasing $\mathrm{pH}$. These findings imply that $\mathrm{NaOH}-\mathrm{catalyzed}$ condensation plays an important role in forming the xerogel containing a low concentration of removable carbonaceous groups and moisture, and in promoting the conversion of the organic-inorganic mixed phase into the inorganic phase at a relatively low temperature.

\section{XEROGEL COATING FILMS}

On the basis of this information, xerogel films were deposited on the Al substrate surfaces by a dipping method. The thickness of $100^{\circ} \mathrm{C}$-dried films, measured with a surface profile system, ranged from 0.6 to $1.2 \mu \mathrm{m}$. The pyrolytic changes and rearrangement in conformation of $100^{\circ} \mathrm{C}$-sintered film samples at $300^{\circ} \mathrm{C}$ were investigated with specular reflectance $\mathrm{IR}$.

Figure 5 shows the changes in the IR spectral features of $300^{\circ} \mathrm{C}$-pyrolyzed xerogel films. The changes in the spectral structure of the $\mathrm{pH} 1.1 \mathrm{film}$ (a), compared with that of a $150^{\circ} \mathrm{C}$. preheated sample (not shown), can be described as follows: 1) the elimination of the peaks at frequencies at 1300 and $1.190 \mathrm{~cm}^{-1}$

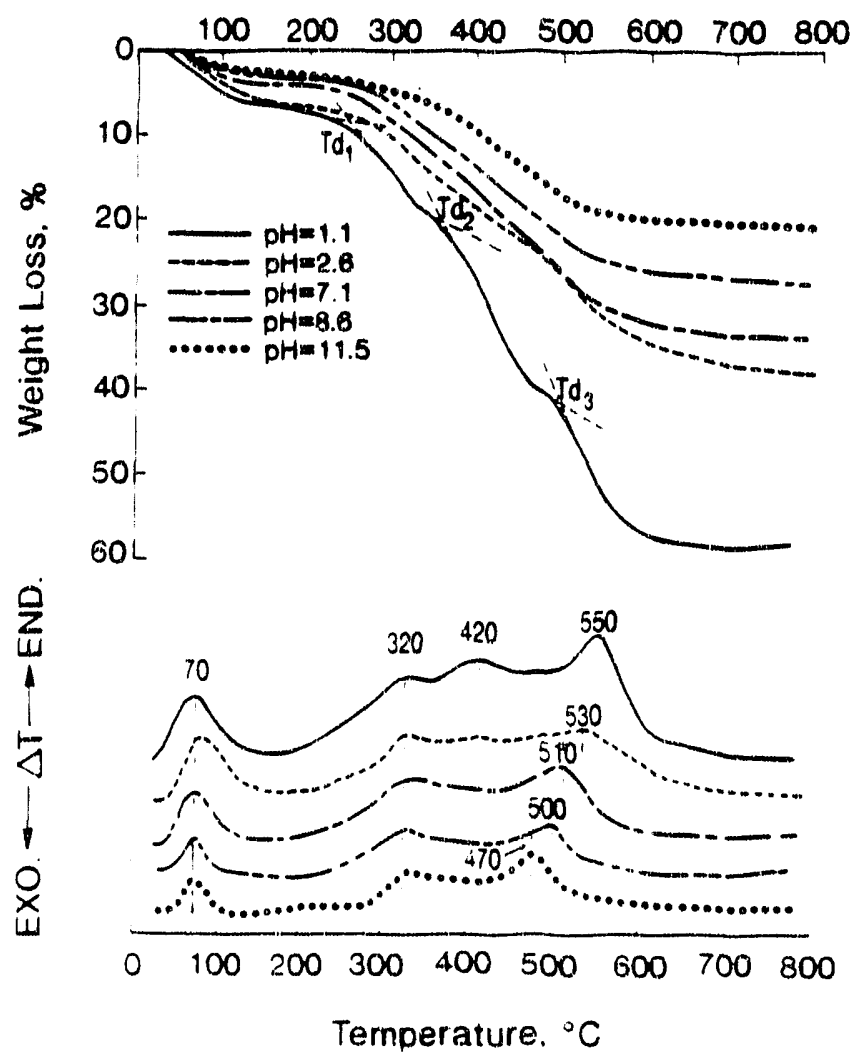

Figure 4. TGA and DTA curves for the pyrolysis of xerogels heated in air at a rate of $10^{\circ} \mathrm{C} / \mathrm{min}$. 
originating from the $\mathrm{Zr}-\mathrm{O}-\mathrm{C}$ and $\mathrm{Si}-\mathrm{C}$ bands, respectively, 2) a shift in the absorption of the Si-O-C band, while its peak intensity becomes much weaker, and 3 ) a shift in the Si-O-Zr band from 930 to $970 \mathrm{~cm}^{-1}$. The first two results are indicative of the removal of many carbonaceous groups from the polymeric organozirconosiloxane networks. Such pyrolytic phenomena will lead to the third result, namely, the PZS network structure at $300^{\circ} \mathrm{C}$ has a high degree of densification of Si-O-Zr linkages. For all of the $\mathrm{NaOH}$ catalyst-induced films, the peak absorbance of the $\mathrm{Si}-\mathrm{O}-\mathrm{Zr}$ band at $970 \mathrm{~cm}^{-1}$ grows conspicuously with the increase in concentration of $\mathrm{NaOH}$, suggesting that the extent of densification of Si-O-Zr linkage in the formed PZS films is related strongly to the $\mathrm{pH}$ of sol. On the other hand, the signal intensity of $\mathrm{Si}-0-\mathrm{Si}$ band at $1010 \mathrm{~cm}^{-1}$ declines with a rise in $\mathrm{pH}$.

The EDX spectrum (not shown) of the $300^{\circ} \mathrm{C}$-pyrolyzed $\mathrm{pH} 1.1$ film, in the absence of an $\mathrm{NaOH}$ catalyst, has three prominent lines, corresponding to $\mathrm{Si}, \mathrm{Zr}$, and $\mathrm{Cl}$ elements. The $\mathrm{Si}$ and $\mathrm{Zr}$ elements virtually belong to the PZS, while the presence of $\mathrm{Cl}$ is associated with the $\mathrm{HCl}$ used as hydrolysis promoter of the alkoxy groups in the TSPI and $\mathrm{Zr}\left(\mathrm{OC}_{3} \mathrm{H}_{6}\right)_{4}$. When the $\mathrm{pH}$ of this HCI catalyst-induced sol was adjusted to 2.6 by adding $\mathrm{NaOH}$, the EDX spectral structure is characterized by a remarkable increase in the signal intensity of $\mathrm{Cl}$, and a signal of $\mathrm{Na}$ emerges. A further increase in $\mathrm{NaOH}$ in the sol system results in the specific features of spectrum, involving a significantly intensified $\mathrm{Cl}$ signal and a growing intensification of the $\mathrm{Na}$ line. Thus, the acceleration of the rate of the condensation reaction by the $\mathrm{NaOH}$ catalyst not only contributes to an increase in densification of $\mathrm{Si-O-Zr}$ linkages, but also promotes the formation of Na-related $\mathrm{Cl}$ compounds as by-products in the PZS layers.

To further demonstrate that the $\mathrm{NaCl}$ by-product had been removed from the PZS layers, we inspected the depth-elemental composition profile in the water-rinsed $\mathrm{pH} 8.6 \mathrm{film}$ layers and in the PZS/ Al interfacial regions, using auger electron spectroscopy (AES) in conjunction with Ar ion sputter-etching. The sputter rate for the depth profiling was $\approx 30 \mathrm{~nm} / \mathrm{min}$. Figure 6 depicts the changes in auger peak heights of representative elements such as $\mathrm{O}, \mathrm{Si}, \mathrm{Zr}, \mathrm{Cl}$, and $\mathrm{Al}$ versus sputter time for the $\mathrm{pH} 8.6 \mathrm{film}$ deposited on Al samples. The $C 1$ at the surface of the film (zero sputter time) had the lowest peak, corresponding to a minor atomic presence. The height of the peak decreased with sputter times and then disappeared at a depth of $\approx 540 \mathrm{~nm}$. This finding i.mplies that there is no $\mathrm{Cl}$ in the PZS layers adjacent to the $\mathrm{Al}$ substrate.

In making water-impermeable xerogel films, the magnitude of wettability of the coating's surfaces by water is among the most important factors governing good protective performance. Therefore, the degree of the water-wettability of the xerogel 


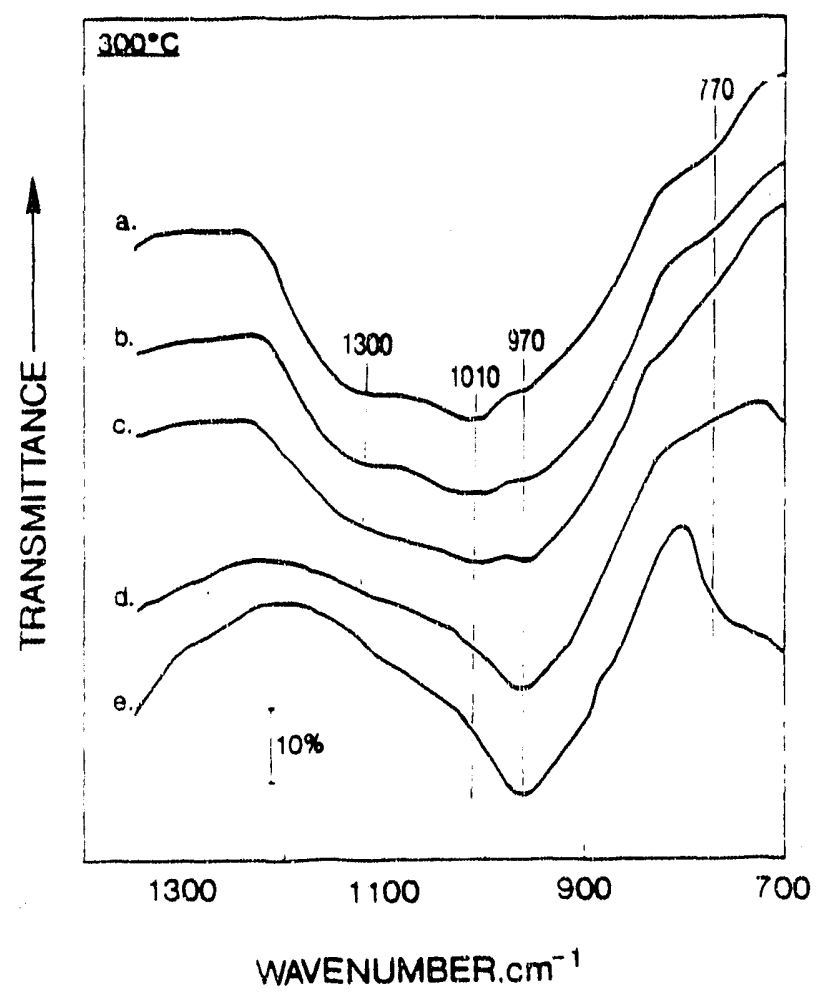

Figure 5. IR spectra for the $300^{\circ} \mathrm{C}$-pyrolyzed xerogels at ph (a) 1.1 (b) 2.6, (c) 8.6, (d) 11.5 , and (e) 12.8 .

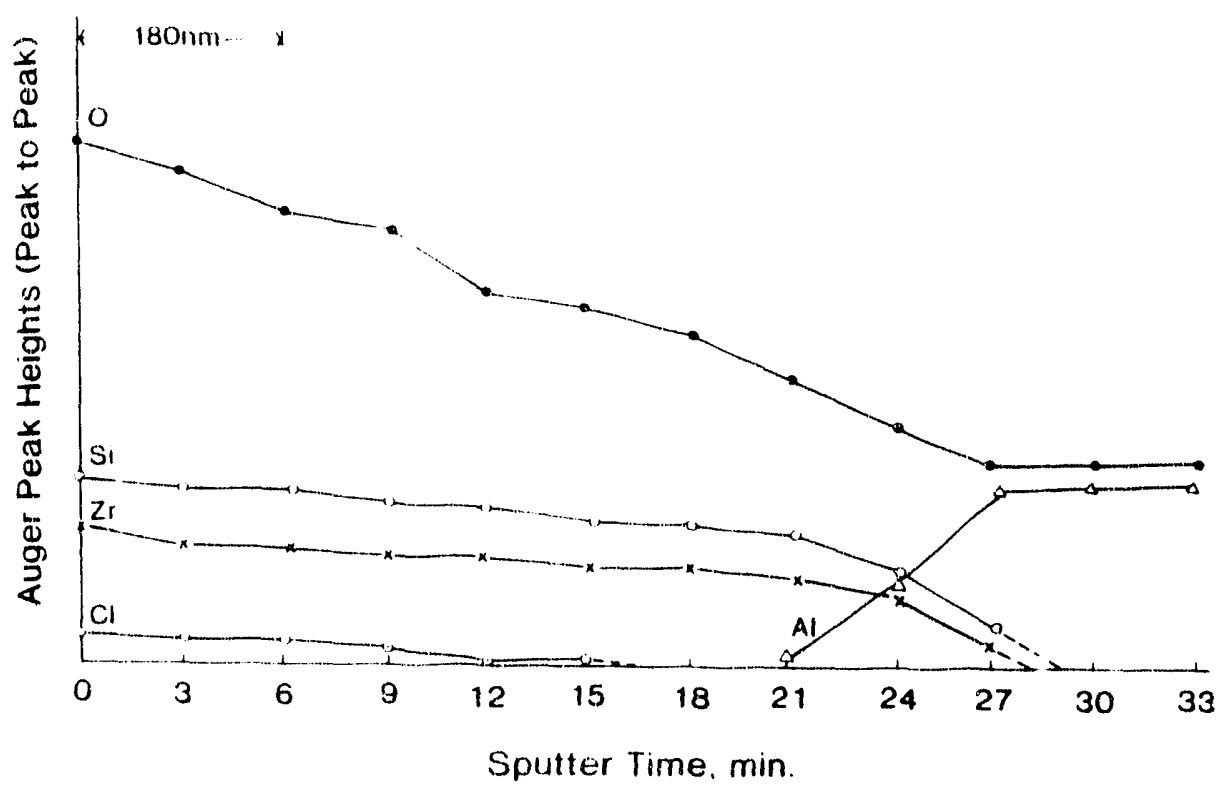

Figure 6. AES depth-profile of pyrolyzed PZS-coated aluninum after rinsing with water. 
film surface was estimated from the average value of the advancing contact angle on this surface. Figure 7 is a plot of $\theta$ (degree) as a function of the film-treating temperatures, for the $\mathrm{pH} 8.6 \mathrm{film}$. Since a high contact angle correlates with a low rate of wetting, the resultant $\theta$-temperature curve showed that film surfaces treated with a high temperature are less wettable. As the film is exposed to high temperatures the original hydrophilic xerogel surfaces are converted to hydrophobic surfaces. The $\theta$ value similar to that of the $250^{\circ} \mathrm{C}$ film was obtained from the $300^{\circ} \mathrm{C}$-treated film, suggesting that PZS films having a minimum water-wetting behavior can be prepared by pyrolysis at temperatures of $\geq 250^{\circ} \mathrm{C}$.

Figure 8 illustrates the variation in $I_{\text {corr }}$ value of $\mathrm{Al}$ substrate as a function of the treating temperatures for $\mathrm{pH} 1.1$, $2.6,7.1,8.6$, and 12.8 sol-derived PZS coating films. The protective ability of the coatings depends primarily on the $\mathrm{pH}$ value of sol precursors and the treatment temperature of films. The $I_{\text {corr }}$ value for the coatings preheated at $100^{\circ} \mathrm{C}$ ranged from - 0.2 to $1.9 \mu \mathrm{A}$. Since a low $I_{\text {corr }}$ value is predictive of good corrosion protection, such a high $I_{\text {corr }}$ represents poor protection. The major reason for the poor protection is due to the hydrophilic nature of coatings, which have a high susceptibility to water-wettability. In fact, all the films were dissolved after immersion for $\approx 10 \mathrm{hr}$ in a water at $25^{\circ} \mathrm{C}$. A reduction in $I_{\text {corr }}$ to a low current density was measured for all filins treated at $200^{\circ} \mathrm{C}$, except for the $\mathrm{pH} 12.8$ coating. Increasing the temperature of treatment to $250^{\circ} \mathrm{C}$ acted to further reduce the $I_{c o r r}$; beyond this temperature, there was only a slight decrease in $I_{\text {corr }}$. Therefore, films treated at temperatures $\geq 250^{\circ} \mathrm{C}$ have the maximum ability to protect Al substrates. In contrast, the $I_{\text {corr }}$ of $200^{\circ} \mathrm{C}$ treated $\mathrm{pH} 1.1 \mathrm{film}$ tends to increase with increased temperature. This phenomenon can be associated with failure of the film, induced by high shrinkage that is related to the liberation of many carbonaceous groups at elevated temperatures, thereby resulting in a poor protection performance. The ability of $300^{\circ} \mathrm{C}$ treated films to protect Al was rated in the following order: $\mathrm{pH}$ $8.6>7.1>2.6>12.8>1.1$. This finding strongly suggested that a dense PZS fractal cluster coating containing a proper proportion of Si-O-Si to Si-0-Zr linkages provides an effective barrier to the corrosion of Al substrate and minimizes the corrosion rates of $\mathrm{Al}$. 


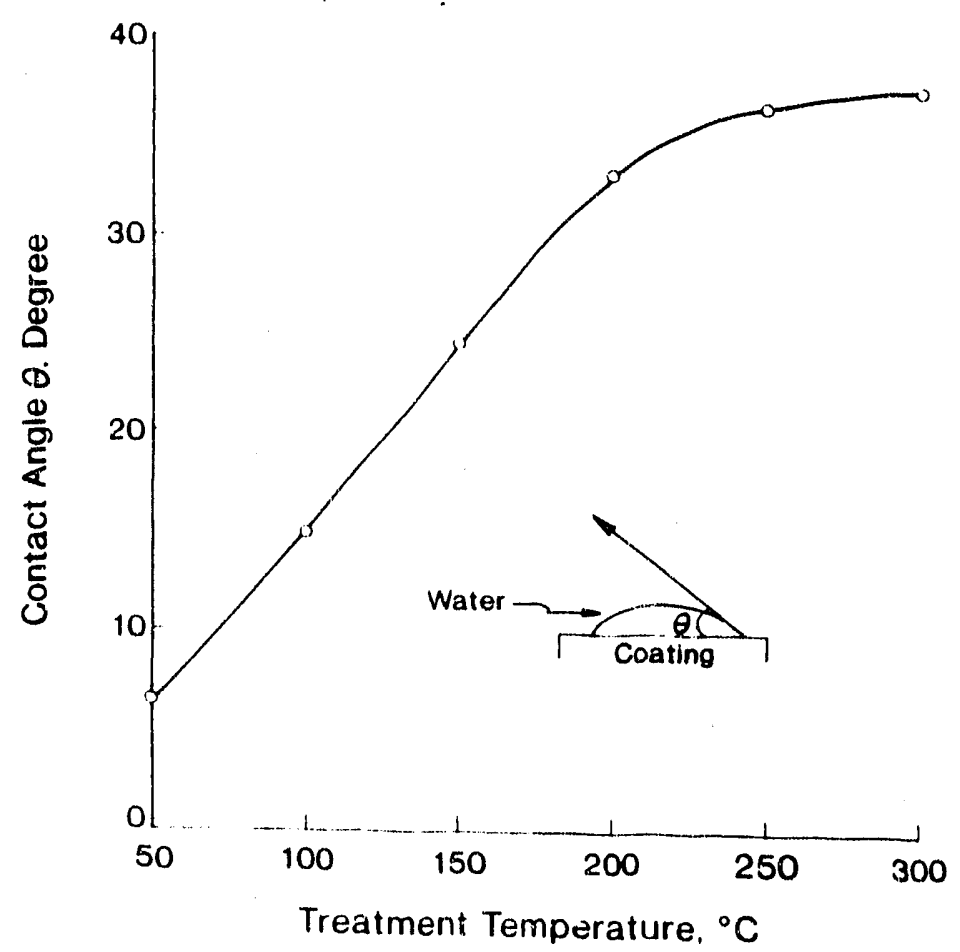

Figure 7. Effect of temperature on the reduction of waterwettability of xerogel film surfaces.

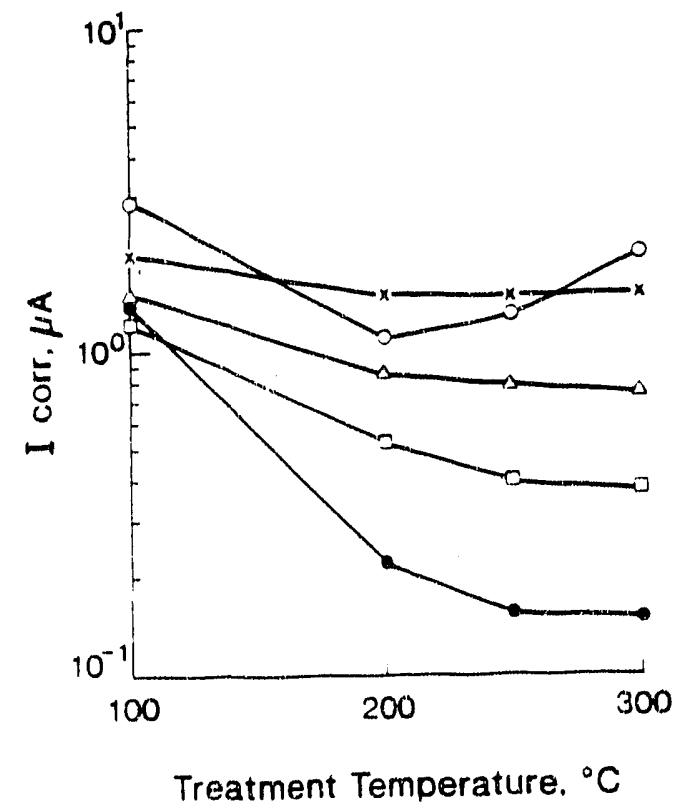

Figure 8. Changes in the corrosion current, Icorr, of PZS xerogel-coated aluminum substrates as a function of temperatures of treatment of the coatings; ph $1.1(0), 2.6(\Delta), 7.1(\square)$, $8.6(-)$, and $12.8(x)$. 
An increase in the $\mathrm{pH}$ of the sol (by adding an appropriate amount of $\mathrm{NaOH}$ ), reflecting the progression of the condensation reaction, led to a significant growth of cluster particles. This cluster growth significantly contributed to a shift in the zeta potential $(z-p)$ of the sol to near zero $\mathrm{mV}$ in the positive potential regions. The morphology of this sol particle was characterized by fractal cluster species having highly, branched microfeatures. These clusters eventually link together to build ideal xerogel films with particle-packing geometries. The isoelectric point (IEP) of the sol, corresponding to the $0 \mathrm{mV}$ of $z-p$, seems to occur around $\mathrm{pH}$ 9.5. The molecular structure of xerogel made from the sol with near IEP at the positive potential sites exhibited a moderate densification of $\mathrm{Si}-\mathrm{O}-\mathrm{Zr}$ linkages, reflecting the deposition of ideal fractal cluster films on the aluminum substrates.

The hydrophobic PZS fractal cluster coating, which is most reliable in protecting the aluminum substrate against $\mathrm{NaCl}$ induced corrosion, can be prepared by the pyrolysis at $250^{\circ}$. $300^{\circ} \mathrm{C}$, of the xerogel film from sol at $\mathrm{pH} 8.6$.

\section{REFERENCES}

1. T. Sugama, L.E. Kukacka, and N. Carciello, Prog. Org. Coat.,11, 173 (1990).

2. T. Sugama, N. Carciello, and C. Taylor, J. Non-Cryst. Solids, 134, 58 (1991).

3. J.D. LeMay, R.W. Hopper, L.W. Hrubesh, and R.W. Pekala, MRS Bulletin, 15, 30 (1990).

4. L. Liepina and V. Kadek, Corros. Sci., 6, 177 (1966).

5. R.T. Foley, Corros., 42, 277 (1986).

\section{DISCLAIMER}

This report was prepared as an account of work sponsored by an agency of the United States Government. Neither the United States Government nor any agency thereof, nor any of their employees, makes any warranty, express or implied, or assumes any legal liability or responsi. bility for the accuracy, completeness, or usefulness of any information, apparatus, product, or process disclosed, or represents that its use would not infringe privately owned rights. Reference herein to any specific commercial product, process, or service by trade name, trademark, manufacturer, or otherwise does not necessarily constitute or imply its endorsement, recommendation, or favoring by the United States Government or any agency thereof. The views and opinions of authors expressed herein do not necessarily state or reflect those of the United States Government or any agency thereof. 
